\title{
Does brain radiotherapy improve survival in patients with esophageal squamous cell carcinoma with brain metastasis?
}

\author{
Gui-Shan Lin $^{1 \#}$, Hua-Chun Luo ${ }^{2 \#}$, Zhi-Chao Fu' ${ }^{2}$, Shao-Guang Liao ${ }^{2}$, Lv-Juan Cai ${ }^{2}$, Jin-Feng Zhu ${ }^{1}$ \\ ${ }^{1}$ Department of Medical Oncology, Fujian Provincial Hospital, Provincial Clinical College, Fujian Medical University, Fuzhou 350000, China; \\ ${ }^{2}$ Department of Radiation Oncology, Joint Logistics 900 Hospital, Fujian Medical University, Fuzhou 350000, China \\ Contributions: (I) Conception and design: ZC Fu; (II) Administrative support: HC Luo, GS Lin; (III) Provision of study materials or patients: HC \\ Luo; (IV) Collection and assembly of data: JF Zhu; (V) Data analysis and interpretation: SG Liao, LJ Cai; (VI) Manuscript writing: All authors; (VII) \\ Final approval of manuscript: All authors. \\ \#The authors contributed equally to this work. \\ Correspondence to: Zhi-Chao Fu. Department of Radiation Oncology, Joint Logistics 900 Hospital, Fujian Medical University, Fuzhou 350000, China. \\ Email: fauster1112@126.com.
}

Background: To investigate the clinical characteristics, influencing factors, and their impact on survival in patients with brain metastases from esophageal squamous cell carcinoma (BM-ESCC).

Methods: A total of 67 patients with patients with newly diagnosed BM-ESCC were retrospectively analyzed from December 2000 to December 2016, in order to examine the correlation between clinicopathological characteristics and brain metastases, and between brain metastases and survival.

Results: The number of BM-ESCC was positively correlated with $\mathrm{T}$ and $\mathrm{N}$ stages $(\mathrm{P}<0.05)$. The higher the $\mathrm{T}$ and $\mathrm{N}$ stages, the higher the incidence. The median survival time was 9.65 months. $\mathrm{N}$ stage was an independent risk factor for BM-ESCC. N0 + N1 was associated with a lower risk of brain metastases $(\mathrm{P}<0.05)$. Patients with 1 brain metastasis had a significantly longer survival than those with 2 and 3 brain metastases. $\mathrm{N}$ stage-stratified analysis revealed that $\mathrm{N} 0+\mathrm{N} 1$ patients had a longer survival than $\mathrm{N} 2$ and N3 patients $(\mathrm{P}<0.05)$. Cox regression analysis revealed that mortality in $\mathrm{T} 3+\mathrm{T} 4$ patients was 2.337 times that of Tis + $\mathrm{T} 1$ patients; mortality in $\mathrm{N} 3$ patients was 3.486 times that of $\mathrm{N} 0+\mathrm{N} 1$ patients; and mortality in untreated patients was 2.772 times that of those treated with whole brain radiotherapy.

Conclusions: The number of BM-ESCC is correlated to T and N stages. The higher the $\mathrm{N}$ stage, the higher risk of brain metastases. The higher of T and N stages in ESCC, the worse in prognosis. Whole brain radiotherapy could offer greater survival benefits.

Keywords: Esophageal squamous cell carcinoma (ESCC); brain metastases (BM); risk factors; prognosis; wholebrain radiotherapy

Submitted Jun 21, 2019. Accepted for publication Feb 10, 2020.

doi: $10.21037 /$ apm.2020.04.23

View this article at: http://dx.doi.org/10.21037/apm.2020.04.23

\section{Introduction}

Esophageal cancer is one of the most common digestive malignancies, and has an increasing incidence in China $(1,2)$. Approximately $30-40 \%$ of adult cancer patients developed brain metastases during treatment (3). The clinical incidence of brain metastases from esophageal cancer is relatively low (4). No effective data analysis has been performed concerning the selection of treatment options and analysis of prognostic factors for patients with brain metastases from esophageal cancer. For patients with short expected survival, the treatment aims to relieve symptoms and improve quality of life (5); while for those with long expected survival, the focuses are on tumor control rate and long-term toxicity (6). The key challenges in offering greater survival benefits for patients with brain metastases from esophageal cancer are 
how to effectively predict the prognosis and develop an appropriate treatment plan. This study was to investigate the clinical characteristics, influencing factors, and their impact on survival in patients with brain metastases from esophageal squamous cell carcinoma (BM-ESCC) to provide evidence for survival assessment and prognosis.

\section{Methods}

\section{Subjects}

A total of 8,673 patients with newly diagnosed esophageal cancer were screened for the study from December 2000 to December 2015. Inclusion criteria: (I) histopathological diagnosis of ESCC; and (II) magnetic resonance imagingconfirmed intracranial metastases. Exclusion criteria: (I) incomplete pathological information; or (II) development of a secondary primary tumor. A total of 67 patients with BMESCC were included in the study, including 31 patients with 1 intracranial metastasis, 24 with 2 intracranial metastases, and 12 with $\geq 3$ intracranial metastases. Twenty-two patients had intracranial metastases only, and 45 had metastases in other vital organs. The International Union Against Cancer (UICC) tumor node metastasis (TNM) classification for esophageal cancer was used. T classification: because of the small number of patients with Tis and T4 cancers, Tis and $\mathrm{T} 1$ were combined, and $\mathrm{T} 3$ and $\mathrm{T} 4$ were combined. $\mathrm{N}$ classification: $\mathrm{N} 0$ and $\mathrm{N} 1$ were combined. The other general information is shown in Table 1. All subjects in the study signed an informed consent form. The protocol was approved by the Medical Ethics Committee of General Fuzhou Hospital (No. 2018-015).

\section{Treatment}

Of the patients with intracranial metastases alone, 3 received surgical resection with postoperative whole brain radiotherapy at $40 \mathrm{~Gy} / 20 \mathrm{f}$. The remaining 19 patients received radiotherapy alone, at a total dose of 56-60 Gy. Of the patients with metastases in other vital organs, 17 had no surgery or radiotherapy, 22 received whole brain radiotherapy, and 6 were treated with a local boost for intracranial metastases following whole brain radiotherapy (at the same dose as previously described).

\section{Follow-up}

All the 67 patients with BM-ESCC were collected from the information base. Clinical information and survival data were collected by clinic or telephone follow-up.

\section{Statistical analysis}

Statistical data were analyzed using SPSS 13.0. Counting data were described by proportion and frequency. Comparison among groups was performed using the chisquare or Fisher's test. Major risk factors of BM-ESCC were analyzed by logistic regression. Survival curve analysis was performed using Kaplan-Meier method and Log rank test, and multivariate prognostic analysis using Cox's regression model. $\mathrm{P}<0.05$ was considered statistically significant.

\section{Results}

\section{Relationship between clinicopathological characteristics and number of brain metastases in patients with BM-ESCC}

Overall, $0.77 \%(67 / 8,673)$ of the 8,673 patients with esophageal cancer developed brain metastases. Of them, $32.8 \%(22 / 67)$ developed brain metastases only, and $67.2 \%$ (45/67) developed multi-organ metastases. There were significant differences in brain metastases between $\mathrm{T}$ stages and between $\mathrm{N}$ stages ( $\mathrm{P}=0.003$ and 0.000 , respectively). The incidence of brain metastases increased with $T$ stage and $\mathrm{N}$ stage. There was no significant difference in brain metastases between gender, age, Karnofsky performance status (KPS), extracranial metastases or primary esophageal lesions $(\mathrm{P}>0.05)$ (see Table 1).

\section{Logistic regression analysis of BM-ESCC}

Logistic regression analysis was performed with the number of BM-ESCC as a dependent variable $(0=1,1=2,3=\geq 3)$, and other clinicopathological characteristics as independent variables and covariates. The results showed that $\mathrm{N}$ stage was an independent risk factor for brain metastases in patients with ESCC. $\mathrm{N} 0+\mathrm{N} 1$ was associated with a lower risk of brain metastases $(\mathrm{P}<0.05)$. A higher $\mathrm{T}$ stage was associated, but not significantly, with an increased risk of brain metastases $(\mathrm{P}>0.05)$ (see Table 2).

\section{Relationship between BM-ESCC and survival prognosis}

As of June 31, 2017, the median follow-up time was 22 months. All the 67 (100.0\%) patients with BM-ESCC were followed up. The median survival time was 9.6 months (0-30 months). Patients with 1 brain metastasis had a significantly longer survival than those with 2 and 3 
Table 1 Relationship between clinicopathological characteristics with brain metastases (n, \%)

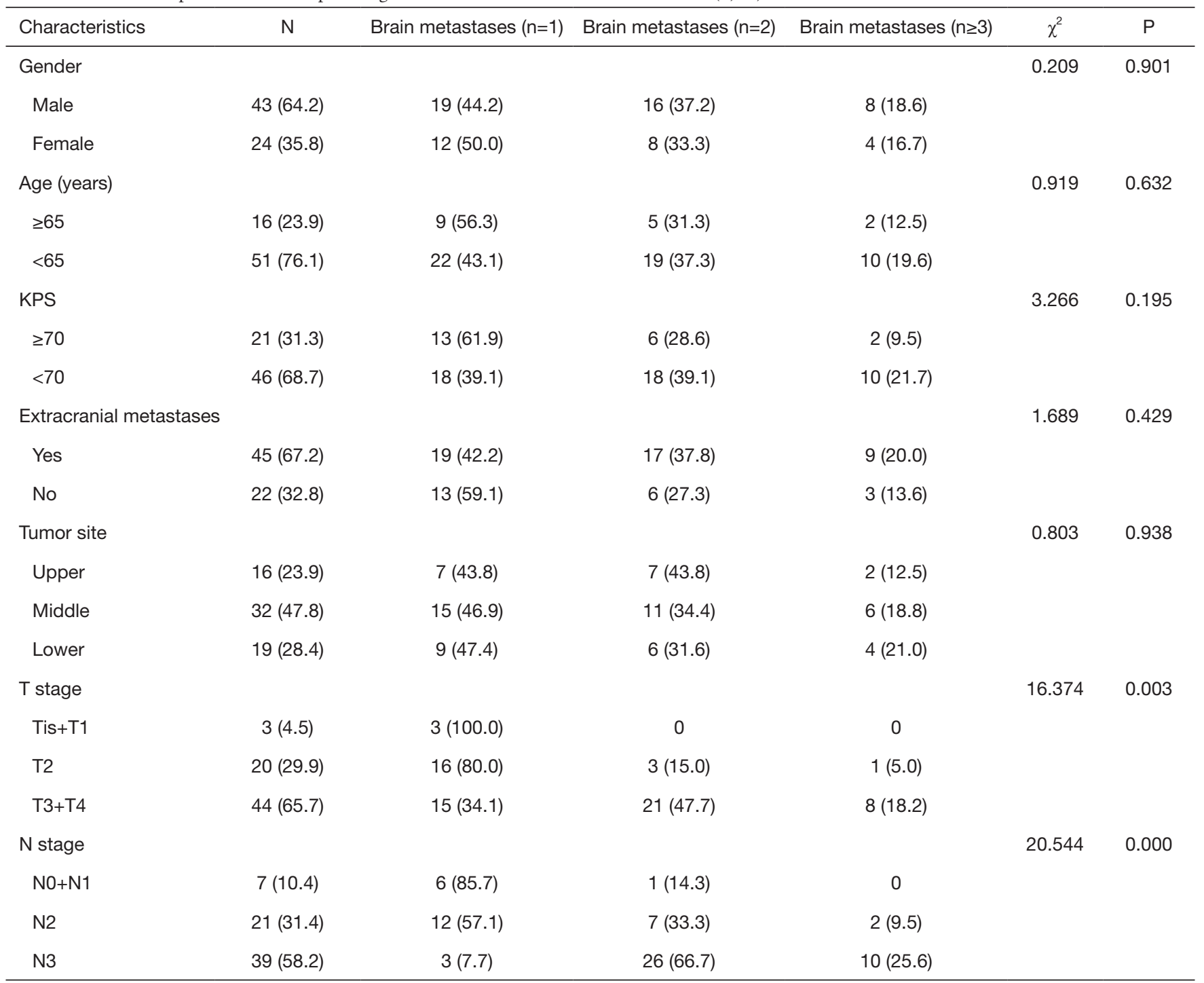

KPS, Karnofsky performance status.

brain metastases (see Figure 1). Stratification analysis was performed according to $\mathrm{N}$ stage, the independent risk factor of brain metastases in logistic regression analysis. The results showed that $\mathrm{N} 0+\mathrm{N} 1$ patients had a significantly longer survival than $\mathrm{N} 2$ and $\mathrm{N} 3$ patients, and N2 patients had a significantly longer survival than N3 patients (both $\mathrm{P}<0.05$ ) (see Figure 2).

\section{Cox multivariate survival regression analysis}

Survival analysis using Cox multivariate regression model revealed that mortality in $\mathrm{T} 3+\mathrm{T} 4$ patients was 2.337 times that of Tis + T1 patients; mortality in N3 patients was 3.486 times that of $\mathrm{N} 0+\mathrm{N} 1$ patients; and mortality in untreated patients was 2.772 times that of those treated with whole brain radiotherapy. There was no significant difference in mortality between the other groups $(\mathrm{P}>0.05)$ (see Table 3$)$.

\section{Discussion}

The incidence of brain metastases from esophageal cancer reported in the literature is inconsistent, with great 
Table 2 Logistic regression analysis of BM-ESCC patients

\begin{tabular}{|c|c|c|c|c|c|c|c|}
\hline Items & B & SE & Wald & $d f$ & $\mathrm{P}$ & OR & $95 \% \mathrm{Cl}$ \\
\hline $\mathrm{Tis}+\mathrm{T} 1$ & -0.496 & 0.261 & 2.487 & 1 & 0.094 & 0.783 & $0.524-1.210$ \\
\hline $\mathrm{T} 2$ & -0.745 & 0.467 & 3.369 & 1 & 0.061 & 0.457 & $0.221-1.045$ \\
\hline $\mathrm{T} 3+\mathrm{T} 4$ & $0 \mathrm{a}$ & - & - & 0 & - & - & - \\
\hline \multicolumn{8}{|l|}{$N$ stage } \\
\hline $\mathrm{N} 0+\mathrm{N} 1$ & -0.776 & 0.327 & 7.586 & 1 & 0.004 & 0.336 & $0.217-0.873$ \\
\hline N2 & -0.692 & 0.241 & 6.787 & 1 & 0.007 & 0.428 & $0.231-0.869$ \\
\hline N3 & $\mathrm{Oa}$ & - & - & 0 & - & - & - \\
\hline
\end{tabular}

BM-ESCC, brain metastases from esophageal squamous cell carcinoma; OR, odds ratio; $\mathrm{Cl}$, confidence interval.

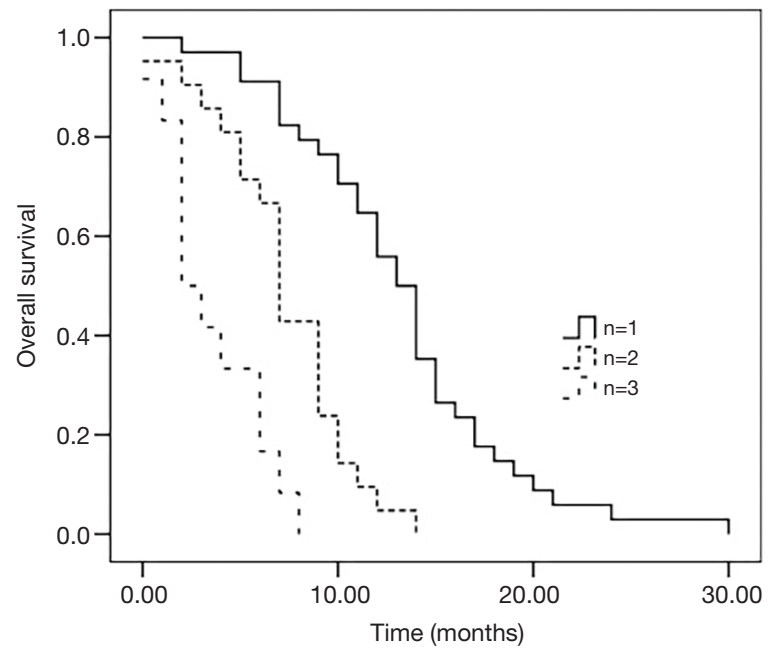

Figure 1 Survival analysis of different number brain metastases in esophageal squamous cell carcinomas.

regional differences, even the esophageal carcinoma rarely metastasizes to the brain, however, more attentions were paid on $(7,8)$. The incidence of concurrent brain metastases in esophageal cancer was $0.77 \%$ in this study, which was inconsistent with the other study (0.77\% vs. 0.16-0.69\%) (9). The differences in pathological type, race, and eating habits are the main reason for this inconsistency, patients and tumor characteristics could be influence factors for the esophageal cancer $(10,11)$, However, further study is required to determine whether there are different biological mechanisms of brain metastasis between pathologic types, and different brain metastasis-related driver genes between races in patients with esophageal cancer. Approximately

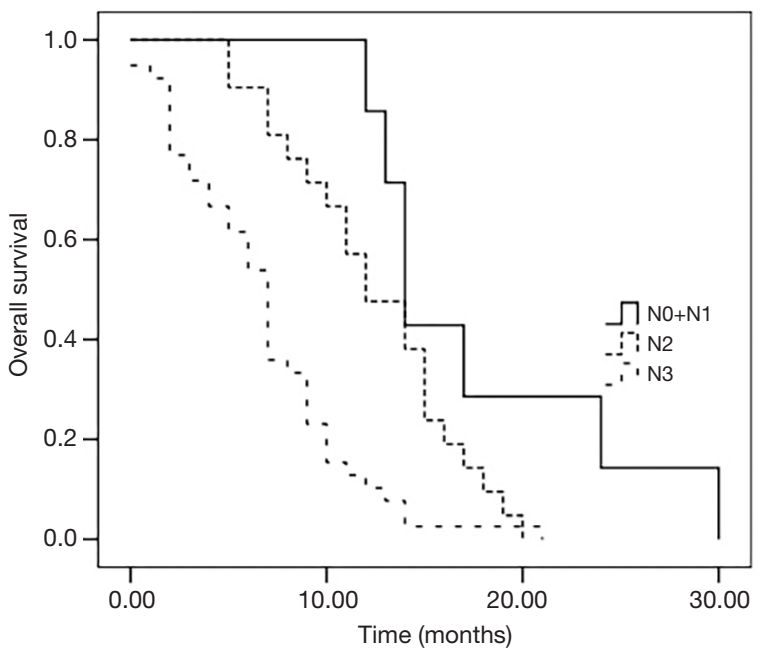

Figure 2 Survival analysis of different $\mathrm{N}$ stage in esophageal squamous cell carcinomas.

$67.2 \%$ of the patients with brain metastases had multiorgan metastases, which is similar to previous reports (12). This study revealed that $\mathrm{T}$ and $\mathrm{N}$ stages were proportional to the number of BM-ESCC. It is indirectly proved that the higher clinical stage and tumor load, the higher rate for the BM-ESCC, A study on the relationship between the rare of complete postoperative pathological remission and prognosis was performed, which confirmed that the higher $\mathrm{T}$ stage, the lower for the rate of clinical pathological remission, but higher the risk of brain metastasis (13), but its sensitivity and specificity need further study. We found that there were no connection between brain metastases and gender, age, KPS, extracranial metastases or primary 
Table 3 Cox multi variate regression analysis of prognostic factors in BM-ESCC patients

\begin{tabular}{|c|c|c|c|c|c|c|c|c|}
\hline Items & $\mathrm{N}$ & B & SE & Wald & $d f$ & $\mathrm{P}$ & OR & $95 \% \mathrm{Cl}$ \\
\hline $\mathrm{Tis}+\mathrm{T} 1$ & 3 & - & - & - & - & - & 1 & - \\
\hline T2 & 20 & 0.487 & 0.296 & 1.382 & 1 & 0.294 & 1.343 & $0.472-3.691$ \\
\hline $\mathrm{T} 3+\mathrm{T} 4$ & 44 & 0.565 & 0.482 & 3.647 & 1 & 0.078 & 1.236 & $0.876-2.694$ \\
\hline $\mathrm{N} 0+\mathrm{N} 1$ & 7 & - & - & - & - & - & 1 & - \\
\hline N2 & 21 & -0.143 & 0.692 & 0.000 & 1 & 0.792 & 0.837 & $0.494-1.643$ \\
\hline N3 & 39 & 1.137 & 0.382 & 5.383 & 1 & 0.001 & 2.141 & $1.037-4.872$ \\
\hline Treatment & & & & 4.494 & 2 & 0.001 & & \\
\hline None & 17 & 1.394 & 0.227 & 3.546 & 1 & 0.000 & 1.431 & $0.391-2.173$ \\
\hline Age (years) & & & & 3.874 & 1 & 0.787 & & \\
\hline$\geq 65$ & 16 & - & - & - & - & - & 1 & - \\
\hline$<65$ & 51 & 0.484 & 0.726 & 1.927 & - & 0.830 & 1.792 & $0.473-2.847$ \\
\hline KPS & & & & 1.763 & 1 & 0.372 & & \\
\hline$\geq 70$ & 21 & - & - & - & - & - & 1 & - \\
\hline$<70$ & 46 & 0.525 & 0.438 & 2.018 & - & 0.547 & 1.287 & $0.343-3.117$ \\
\hline Extracranial metastases & & & & 1.054 & 1 & 0.136 & & \\
\hline
\end{tabular}

BM-ESCC, brain metastases from esophageal squamous cell carcinoma; OR, odds ratio; Cl, confidence interval; KPS, Karnofsky performance status.

esophageal lesions. It is speculated that BM-ESCC are mainly related to the biological behavior of tumor cells, and not directly related to the physiological characteristics of patients. For patients with esophageal cancer, brain metastases mostly occurred 1 year after diagnosis of esophageal cancer, and radiographic assessment was performed according to neurological symptoms and related signs (14).

In this study, $72.7 \%$ and $61.5 \%$ of patients in a stage higher than $\mathrm{T} 3$ and $\mathrm{N} 3$, respectively, had $\geq 2$ brain metastases. Due to the limited sample size, T3 and T4 were combined, which might have led to a bias in the research results. Further study with a larger sample size is needed to determine whether it is more accurate to use I-IV stages in assessment. T stage is an important indicator of advanced
ESCC. The higher the T stage, the greater the likelihood of metastasis (15). Logistic regression analysis revealed that a higher $\mathrm{T}$ stage was associated with an increased risk of brain metastases in patients with BM-ESCC. However, there was no statistical difference, which may be related to the small sample size. $\mathrm{N}$ staging is of great significance for the choice of treatment of esophageal cancer, and it is an independent risk factor for the evaluation of prognosis based on the chemotherapy using paclitaxel (16). This study yielded similar results. The risk of brain metastases was significantly lower in $\mathrm{N} 0+\mathrm{N} 1$ patients than in $\mathrm{N} 2$ and $\mathrm{N} 3$ ones. This provides indirect evidence that $\mathrm{N}$ staging is more effective than $\mathrm{T}$ staging in predicting prognosis. The results are similar to the conclusion of Kanemoto et al. (12). This conclusion is further confirmed by the $\mathrm{N}$ stage-stratified 
prognosis analysis. In this study, the median survival time of patients with BM-ESCC was 9.65 months. This is higher than that reported by Weinbery et al. (17), but similar to the reports of Chinese researchers (18). The reason for this difference may be associated with the major pathological type of subjects, which is adenocarcinoma in Europe and the United States, and squamous carcinoma in Asia (19). In addition, this study found that the number of brain metastases in patients with ESCC was positively correlated with long-term survival. However, this factor was not considered in previous studies $(17,18)$, which may result in bias in the results. Common treatments for brain metastases from solid tumors, including esophageal cancer, are whole brain radiotherapy, stereotactic radiotherapy, and surgery.

There was no difference in survival between the treatments in patients with 1-4 brain metastases (20). however, neurological death or survival had been found in patients with a single metastasis by other randomized studies (21), which could bias the research study. This study found that whole brain radiotherapy significantly decreased the mortality in patients with BM-ESCC. It is speculated that whole brain radiotherapy can improve the local control rate of metastases, inhibit intracranial micrometastases, and reduce neurological death (22). This finding is similar to previous reports (23). $\mathrm{T}$ and $\mathrm{N}$ stages of primary esophageal tumors are proportional to mortality. It indirectly suggests that the volume of gastrointestinal tumors is closely related to prognosis $(24,25)$. However, only a small number of subjects were included in the study, due to the low incidence of BM-ESCC. Moreover, the correlation between overexpression of genotypes, such as Her-2, and brain metastases from esophageal cancer was not examined (26). These are the limitations of this study.

\section{Conclusions}

In summary, the number of brain metastases is closely related to $\mathrm{T}$ and $\mathrm{N}$ stages in patients with BM-ESCC. The higher the $\mathrm{T}$ stage, and especially the $\mathrm{N}$ stage, the greater the risk of brain metastases. The smaller the number of brain metastases, the better the prognosis. Moreover, the lower the $\mathrm{N}$ stage of esophageal tumors, the better the prognosis. Whole brain radiotherapy can significantly reduce the mortality in patients with BM-ESCC.

\section{Acknowledgments}

We thank all the survey respondents who participated in the study and the survey field staff who did the interviews. We acknowledge in situation that were providing administrative and logistical support to data collection: Joint Logistics 900 Hospital, Fuzhou, China; The Cancer Organization of Fujian Province; We thank Jian Hua Wu, Na Li for promoting the survey. Dong-Shi Li for many helpful suggestions.

Funding: This study is supported by Medical innovation project of Fujian Health Committee (Grant No. 2018-CX-3).

\section{Footnote}

Conflicts of Interest: All authors have completed the ICMJE uniform disclosure form (available at http://dx.doi. org/10.21037/apm.2020.04.23). The authors have no conflicts of interest to declare.

Ethical Statement: The authors are accountable for all aspects of the work in ensuring that questions related to the accuracy or integrity of any part of the work are appropriately investigated and resolved. The protocol was approved by the Medical Ethics Committee of General Fuzhou Hospital (No. 2018-015).

Open Access Statement: This is an Open Access article distributed in accordance with the Creative Commons Attribution-NonCommercial-NoDerivs 4.0 International License (CC BY-NC-ND 4.0), which permits the noncommercial replication and distribution of the article with the strict proviso that no changes or edits are made and the original work is properly cited (including links to both the formal publication through the relevant DOI and the license). See: https://creativecommons.org/licenses/by-nc-nd/4.0/.

\section{References}

1. Siegel RL, Miller KD, Jemal A. Cancer Statistics, 2017. CA Cancer J Clin 2017;67:7-30.

2. Chen $\mathrm{W}$, Zheng R, Baade PD, et al. Cancer statistics in China,2015. CA Cancer J Clin 2016;66:115-32.

3. Tsao MN, Rades D, Wirth A, et al. Radiotherapeutic and surgical management for newly diagnosed brain metastasis(es): An American Society for Radiation Oncology evidence-based guideline. Pract Radiat Oncol 2012;2:210-25.

4. Spallone A, Izzo C. Esophageal cancer presenting as a brain metastasis: a case report. Oncol Lett 2013;6:722-4.

5. Rades D, Kiechebusch S, Lohynska R, et al. Reduction 
of overall treatment time in patients irradiated for more than three brain metastases. Int J Radiat Oncol Biol Phys 2007;69:1509-13.

6. Rades D, Panzner A, Dziggel L, et al. Dose-escalation of whole-brain radiotherapy for brain metastasis in patients with a favorable survival prognosis. Cancer 2012;118:3852-9.

7. Yoshida S. Brain metastasis in patients with esophageal carcinoma. Surg Neurol 2007;67:288-90.

8. Feng $W$, Zhang $\mathrm{P}$, Zheng X. Neuroimaging and clinical characteristics of brain metastases from esophageal carcinoma in Chinese patients. J Cancer Res Ther 2014;10 Suppl:296-303.

9. Cavanna L, Seghini P, Di Nunzio C, et al. Gastric cancer with brain metastasis and the role of human epidermal growth factor 2 status. Oncol Lett 2018;15:5787-91.

10. Parvin S, Firouz S. A study of 415 cases of esophageal carcinoma in north west of Iran. Med J Malaysia 2003;58:429-31.

11. Rades D, Dziggel L, Bartscht T, et al. Predicting overall survival in patients with brain metastases from esophageal cancer. Anticancer Res 2014;34:6763-5.

12. Kanemoto A, Hashimoto T, Harada H, et al. Occurrence and clinical features of brain metastasis after chemoradiotherapy for esophageal carcinoma. J Radiat Res 2011;52:509-15.

13. Wadhwa R, Taketa T, Correa AM, et al. Incidence of brain metastases after trimodality therapy in patients with esophageal or gastroesophageal cancer: implications for screening and surveillance. Oncology 2013;85:204-7.

14. Smith RS, Miller RC. Incidence of brain metastasis in patients with esophageal carcinoma. World J Gastroenterol 2011;17:2407-10

15. Chen X, Chen J, Zheng X, et al. Prognostic factors in patients with thoracic esophageal carcinoma staged PT14aN0M0 undergone esophagectomy with three-field lymphadenectomy Ann Transl Med 2015;3:282-8.

16. $\mathrm{Hu} \mathrm{Y,} \mathrm{Hu} \mathrm{C,} \mathrm{Zhang} \mathrm{H}$, et al. How does the number of resected lymph nodes influence TNM staging and prognosis for esophageal carcinoma? Ann Surg Oncol 2010;17:784-90.

17. Weinberg JS, Suki D, Hanbali F, et al. Metastasis of esophageal carcinoma to the brain. Cancer 2003;98:1925-33.

18. Song X, Li HW, Song H. The prognosis analysis for Brain metastases from esophageal carcinoma. Chinese Journal of Digestion 2017;37:106-9.

19. He L, Chapple A, Liao Z, et al. Bayesian regression analyses of radiation modality effects on pericardial and pleural effusion and survival in esophageal cancer. Radiother Oncol 2016;121:70-4.

20. Kocher M, Soffietti R, Abacioglu U, et al. Adjuvant wholebrain radiotherapy versus observation after radiosurgery or surgical resection of one to three cerebral metastases: results of the EORTC 22952-26001 study. J Clin Oncol 2011;29:134-41.

21. Owen S, Souhami L. The management of brain metastases in non-small cell lung cancer. Front Oncol 2014;4:248.

22. Rodrigues G, Zindler J, Warner A, et al. Propensity-score matched pair comparison of whole brain with simultaneous in-field boost radiotherapy and stereotactic radiosurgery. Radiother Oncol 2013;106:206-9.

23. Aoyama H, Shirato H, Tago M, et al. Stereotactic radiosurgery plus whole-brain radiation therapy vs. stereotactic radiosurgery alone for treatment of brain metastases. JAMA 2006;295:2483-91.

24. Huang CM, $\mathrm{Xu} M$, Wang JB, et al. Is tumor size a predictor of preoperative $\mathrm{N}$ staging in T2-T4a stage advanced gastric cancer? Surg Oncol 2014;23:5-10.

25. Zu H, Wang F, Ma Y, et al. Stage-stratified analysis of prognostic significance of tumor size in patients with gastric cancer. PloS One 2013,8:e54502.

26. Abu Hejleh T, Deyounq BR, Enqelman E, et al. Relationship between HER-2 overexpression and brain metastasis in esophageal cancer patients. World J Gastrointest Oncol 2012;4:103-8.
Cite this article as: Lin GS, Luo HC, Fu ZC, Liao SG, Cai LJ, Zhu JF. Does brain radiotherapy improve survival in patients with esophageal squamous cell carcinoma with brain metastasis? Ann Palliat Med 2020;9(3):637-643. doi: 10.21037/apm.2020.04.23 